\title{
Editorial
}

\section{The Biopsychosocial Model Thirty Years Later}

\author{
Giovanni A. Fava ${ }^{a, c}$ Nicoletta Sonino ${ }^{b, c}$ \\ ${ }^{a}$ Department of Psychology, University of Bologna, Bologna, and ${ }^{b}$ Department of Statistical Sciences, University of \\ Padova, Padova, Italy; ' Department of Psychiatry, State University of New York at Buffalo, Buffalo, N.Y., USA
}

Thirty years ago George L. Engel [1] highlighted the inadequacies and limitations of the traditional biomedical model and advocated the endorsement of a biopsychosocial approach. The article had a considerable impact on the scientific community and attracted nearly 1,900 citations over the years. The biopsychosocial model allows illness to be viewed as a result of interacting mechanisms at the cellular, tissue, organismic, interpersonal and environmental levels. Accordingly, the study of every disease must include the individual, his/her body and his/her surrounding environment as essential components of the total system [1, 2]. Psychosocial factors may operate to facilitate, sustain or modify the course of illness, even though their relative weight may vary from illness to illness, from one individual to another and even between 2 different episodes of the same illness in the same individual. The key characteristic of clinical science is its explicit attention to humanness, where 'observation (outer viewing), introspection (inner viewing), and dialogue (interviewing) are the basic methodologic triad for clinical study and for rendering patient data scientific' [3, p. 59]. Engel identified the biopsychosocial model as a more complete conceptual framework to guide clinicians in their everyday work with patients. He thought that the transition from the narrow biomedical model to the biopsychosocial model was the major challenge to medicine in the seventies [1].

Has the challenge been met? Not at all, as examined in a recent monograph on the biopsychosocial approach [4].
As 30 years ago, the dominant model of disease today is biomedical, with molecular biology being the basic scientific discipline. Indeed, there has been a progressive decline of clinical observation as the primary source of scientific challenges [5]. Yet, the evidence supporting the biopsychosocial model has considerably increased over the years. A large body of research has documented the role of stressful life events and repeated or chronic environmental challenge in modulating individual vulnerability to illness [6]. The tendency to experience and communicate psychological distress in the form of physical symptoms and to seek medical help for them is a widespread clinical phenomenon that may involve up to 30 or $40 \%$ of medical patients and increases medical utilization and costs $[7,8]$. Medically unexplained symptoms appear to be the rule in primary care $[7,8]$ and the traditional boundaries among medical specialties, based mostly on organ systems (e.g. cardiology, gastroenterology) appear to be more and more inadequate in dealing with symptoms and problems which cut across organ system subdivisions and require a holistic approach. Moreover, affective disturbances (such as depression, anxiety, hostility) and illness behavior, the ways in which individuals experience, perceive, evaluate and respond to their own health status, may affect the course, therapeutic response and outcome of a given illness episode [7].

Psychological well-being [9] was found to play a protective role in the dynamic balance between health and disease outlined by Engel [1]. The need to include consid-

\section{KARGER}

Fax +4161306 1234

E-Mail karger@karger.ch

www.karger.com (c) $2008 \mathrm{~S}$. Karger AG, Basel

0033-3190/08/0771-0001\$24.50/0

Accessible online at:

www.karger.com/pps
Giovanni A. Fava, MD

Dipartimento di Psicologia

University of Bologna, Viale Berti Pichat, 5

IT-40127 Bologna (Italy)

Tel. +39 0512091 339, Fax +39 051243 086, E-Mail giovanniandrea.fava@unibo.it 
eration of function in daily life, productivity, performance of social roles, intellectual capacity, emotional stability and well-being, has emerged as a crucial part of clinical investigation and patient care [7]. These issues have become particularly important in chronic diseases where cure cannot take place and also extend to health providers as well as family caregivers of chronically ill patients, whose emotional burden has become more and more manifest. Patients have become increasingly aware of these problems. Their difficulties in coping with medical illness and its psychological consequences have indeed led to the development of several patients' associations. In controlled investigations for a number of medical disorders, the use of psychotherapeutic strategies has yielded a substantial improvement in quality of life, coping and the course of disease $[7,10]$.

At present, almost all of health care spending is directed at biomedically oriented care. Still, half of the deaths that take place in the USA can be attributed to 'largely preventable behaviors and exposure', such as tobacco smoking, obesity and physical inactivity [11].
In 1985 Geoffrey Rose [12] showed that risk factors for health are almost always normally distributed and supported a general population approach to prevention, instead of targeting those at the highest risk. The exponential spending on preventive pharmaceuticals justified by the potential long-term benefits to a very small segment of the population has now been challenged $[13,14]$, whereas the benefits of modifying lifestyle by population-based measures in a biopsychosocial approach to medical care are increasingly demonstrated $[7,14,15]$.

As George Engel [1] stated 30 years ago '... nothing will change unless or until those who control resources have the wisdom to venture off the beaten path of exclusive reliance on biomedicine as the only approach to health care' (p. 135).

\section{Acknowledgment}

G.A.F. was a medical student in Dr. Engel's unit in 1975.

\section{References}

1 Engel GL: The need for a new medical model: a challenge for biomedicine. Science 1977; 196:129-136.

2 Engel GL: The biopsychosocial model and medical education: who are to be teachers? $\mathrm{N}$ Engl J Med 1982;306:802-805.

3 Engel GL: From biomedical to biopsychosocial. Psychother Psychosom 1997;66:57-62.

4 White P (ed): Biopsychosocial Medicine. Oxford, Oxford University Press, 2005.

5 Feinstein AR: The intellectual crisis in clinical science: medaled models and muddled mettle. Perspect Biol Med 1987;30:215-230.

6 McEwen BS: Protective and damaging effects of stress mediators. N Engl J Med 1998; 338:171-179.
7 Fava GA, Sonino N: The clinical domains of psychosomatic medicine. J Clin Psychiatry 2005;66:849-858.

8 Barsky AJ, Orav EJ, Bates DW: Somatization increases medical utilization and costs independent of psychiatric and medical comorbidity. Arch Gen Psychiatry 2005;62:903910.

9 Ryff CD, Singer BH: Psychological well-being. Psychother Psychosom 1996;65:14-23.

10 Layard R: The case for psychological treatment centres. BMJ 2006;332:1030-1032.
11 Mokdad AH, Marks JS, Stroup DF, Gerberding JL: Actual causes of death in the United States, 2000. JAMA 2004;291:1238-1245.

12 Rose G: Sick individuals and sick populations. Int J Epidemiol 1985; 14:32-38.

13 Heath I: Combating disease mongering daunting but nonetheless essential. PLoS Med 2006;3:e146.

14 Abramson J, Wright JM: Are lipid-lowering guidelines evidence-based? Lancet 2007;369: 168-169.

15 Chiave SE, McCullough ML, Sacks FM, Rimm EB: Healthy lifestyle factors in the primary prevention of coronary heart disease among men. Circulation 2006;114:160167. 